\title{
The relationship between personal factors and its effect on internet usage
}

\begin{abstract}
The use of communication technology is growing rapidly in colleges and universities. The objectives of this study are to identify the effect between age, level of the study, field of the study, gender and income on attitudes toward the Internet, problems in using the Internet and gratification of Internet usage. The present study used the quantitative method by means of a questionnaire survey as a means of achieving its objectives. Sample size for this study is 440 and University Putra Malaysia is chosen as a location. Also quota sampling applied for this investigation. Personal factors in this study include (age, gender, income, level of study and field of study) of respondents. The findings of the study revealed significant relationships between age and attitudes towards Internet, problems in using the Internet and gratification of Internet usage. In addition, there is a significant relationship between educational achievement level and problems in using the Internet. There is a significant relationship between income and attitudes towards Internet, problems in using the Internet and gratification Internet usage.
\end{abstract}

Keyword: Internet usage; Age; Level of education; Gender; Field of study; Income; Attitudes toward internet; Problems in using internet; Gratifications of using internet; Malaysia 